\title{
Hedyotis Diffusa Willd extract induces apoptosis via activation of the mitochondrion-dependent pathway in human colon carcinoma cells
}

\author{
JIUMAO LIN ${ }^{1 *}$, YOUQIN CHEN ${ }^{2,4^{*}}$, LIHUI WEI ${ }^{1}$, XUZHEN CHEN $^{1}$, WEI XU $^{3}$, \\ ZHENFENG HONG ${ }^{1}$, THOMAS J. SFERRA ${ }^{2,4}$ and JUN PENG ${ }^{1}$ \\ ${ }^{1}$ Fujian Academy of Integrative Medicine and ${ }^{3}$ Department of Pharmacology, Fujian University \\ of Traditional Chinese Medicine, 1 Huatuo Road, Minhou Shangjie, Fuzhou, Fujian 350108, P.R. China; \\ Departments of ${ }^{2}$ Pediatrics and ${ }^{4}$ Biochemistry and Molecular Biology, The University of Oklahoma \\ Health Sciences Center, 940 Stanton L. Young Boulevard, Oklahoma City, OK 73190, USA
}

Received June 9, 2010; Accepted August 2, 2010

DOI: 10.3892/ijo_00000785

\begin{abstract}
Hedyotis Diffusa Willd has been used as a major component in several Chinese medicine formulations for the clinical treatment of colorectal cancer. However, the molecular mechanism of the anti-cancer activity of Hedyotis Diffusa Willd remains unclear. In the present study, we investigated the cellular effects of the ethanol extract of Hedyotis Diffusa Willd (EEHDW) in the HT-29 human colon carcinoma cell line. We found that EEHDW inhibited the growth of HT-29 cells demonstrating EEHDW-induced cell morphological changes and reduced cell viability in a dose- and timedependent manner. Furthermore, we observed that EEHDW treatment resulted in DNA fragmentation, loss of plasma membrane asymmetry, collapse of mitochondrial membrane potential, activation of caspase- 9 and caspase- 3 , and increase of the ratio of pro-apoptotic Bax to anti-apoptotic Bcl-2, suggesting that the HT-29 cell growth inhibitory activity of EEHDW was due to mitochondrion-mediated apoptosis, which may partly explain the anti-cancer activity of Hedyotis Diffusa Willd.
\end{abstract}

Correspondence to: Dr Jun Peng, Fujian Academy of Integrative Medicine, Fujian University of Traditional Chinese Medicine, 1 Huatuo Road, Minhou Shangjie, Fuzhou, Fujian 350108, P.R. China E-mail: pjunlab@hotmail.com

${ }^{*}$ Contributed equally

Abbreviations: CRC, colorectal cancer; EEHDW, ethanol extract of Hedyotis Diffusa Willd; DMSO, dimethyl sulfoxide; MTT, 3-(4, 5-dimethyl-thiazol-2-yl)-2,5-diphenyltetrazolium bromide

Key words: apoptosis, colorectal cancer, HT-29 cells, herbal medicine, mitochondria, Hedyotis Diffusa Willd

\section{Introduction}

Colorectal cancer (CRC) is one of the leading causes of death in Western countries, and the incidence of this disease is also increasing in Asian countries (1). To date, chemotherapy is the main therapeutic approach for patients with advanced CRC; and 5-fluorouracil (5-FU)-based regimens are the standard treatment for these patients. However, due to drug resistance, systemic chemotherapy using 5-FU-based regimens produces objective response rates of $<40 \%(2-4)$. Moreover, many currently used chemotherapeutic agents for cancer therapy have potent cytotoxic effects in normal cells and may induce DNA mutations that probably lead to secondary cancers (5). Both drug resistance and toxicity against normal cells limit the effectiveness of current CRC chemotherapy, thus increasing the necessity for the development of new therapeutic approaches $(6,7)$. Natural products that have relatively fewer side-effects have been used clinically in China for thousands of years as important alternative remedies for a variety of diseases. Recently many researchers have investigated these and other natural products to discover novel anti-cancer agents (8-11). Hedyotis Diffusa Willd, belonging to the Rubiaceae family, is a medicinal herb widely distributed in Northeast Asia. As a well-known traditional Chinese folk-medicine, it is used for heat-clearing, detoxification, promotion of blood circulation and removal of blood stasis (12). Hedyotis Diffusa Willd has long been used as an important component in formulated prescriptions of Chinese traditional medicine to treat various types of cancer, including stomach and colon cancers (12-14). However, the precise mechanism of the potential tumorcidal activity of Hedyotis Diffusa Willd remains to be elucidated.

Cell death by apoptosis eliminates excess, redundant, abnormal cells in animals and hence is crucial for animal development and tissue homeostasis. Disturbed regulation of this vital process represents a major causative factor in the pathogenesis of cancers including CRC (15-17). Bcl-2 family proteins are key regulators of apoptosis $(15,16)$, functioning as either suppressors such as Bcl-2, or promoters such as Bax. 
One possible mechanism by which Bcl-2 family proteins regulate apoptosis is through their influence on the permeability of mitochondrial outer membrane (MOM) following homo- or hetero-association (18). It has been demonstrated that after activation, the pro-apoptotic Bax or Bak is sufficient to induce mitochondrial outer membrane permeabilization (MOMP) (19-22), releasing apoptogenic proteins such as cytochrome $\mathrm{c}$ and Diablo/Smac that trigger apoptosis by activating caspases and nucleases (22-26). The anti-apoptotic Bcl-2 protein may bind to active Bax to prevent it from damaging the MOM $(19,26-28)$. The ratio of active anti- and pro-apoptotic Bcl-2 family members determines the fate of cells, and alteration of the ratio by aberrant expression of these proteins impairs the normal apoptotic program contributing to various apoptosis-related diseases $(29,30)$. For instance, overexpression of $\mathrm{Bcl}-2$ is commonly found in various cancers (31), which not only confers a survival advantage to the cancer cells but also causes resistance to conventional chemo- and radio-therapies. Therefore, promoting cell apoptosis via regulating the $\mathrm{Bcl}-2$ family proteins has been the main focus in the development of anti-cancer therapies.

In order to extend the clinical observations of the potential anti-cancer effect of Hedyotis Diffusa Willd and help to establish a scientific foundation for further research, in this study, we evaluated the effect of the ethanol extract of Hedyotis Diffusa Willd (EEHDW) on the growth and apoptosis of HT-29 human colon carcinoma cells, and investigated the possible molecular mechanisms mediating its biological effect. We found that EEHDW inhibited the growth and induced apoptosis of HT-29 cells. EEHDW-induced apoptosis was accompanied by loss of mitochondrial membrane potential $(\Delta \psi \mathrm{m})$, caspase-9 and caspase-3 activation and up-regulation of Bax to Bcl-2 ratio. Our finding suggests that promotion of cancer cell apoptosis via activation of the mitochondriondependent pathway probably is one of the mechanisms by which Hedyotis Diffusa Willd can be effective in the treatment of cancer.

\section{Materials and methods}

Materials and reagents. Dulbecco's modified Eagle's medium (DMEM), fetal bovine serum (FBS), penicillin-streptomycin, trypsin-EDTA, TRIzol reagent and iBlot Western detection stack/iBlot dry blotting system, 5,5',6,6'-tetrachloro-1,1',3,3'tetraethyl-benzimidazol-carbocyanine iodide (JC-1), DNA ladder detection kit, caspase- 3 and -9 colorimetric protease assay kits were purchased from Invitrogen (Grand Island, NY, USA). SuperScript II reverse transcriptase was provided by Promega (Madison, WI, USA). Bcl-2 and Bax antibodies, horseradish peroxidase (HRP)-conjugated secondary antibodies were obtained from Cell Signaling (Beverly, MA, USA). A fluorescein isothiocyanate (FITC)-conjugated Annexin $\mathrm{V}$ apoptosis detection kit was provided by BectonDickinson (San Jose, CA, USA). All the other chemicals used, unless otherwise stated, were obtained from Sigma Chemicals (St. Louis, MO, USA).

Preparation of ethanol extract from Hedyotis Diffusa Willd. Hedyotis Diffusa Willd (500 g) were extracted with $5000 \mathrm{ml}$ of $85 \%$ ethanol using refluxing method and filtered. The ethanol solvent was then evaporated on a rotary evaporator (Shanghai Yarong, Model RE-2000, China). The resultant solution was concentrated to a relative density of 1.05 , and the dried powder of ethanol extract of Hedyotis Diffusa Willd (named EEHDW) was obtained by spraying desiccation method using a spray dryer (Buchi, Model B-290, Switzerland). Stock solutions of EEHDW were prepared by dissolving the EEHDW powder in $40 \%$ DMSO to a concentration of $400 \mathrm{mg} / \mathrm{ml}$, and stored at $-20^{\circ} \mathrm{C}$. The working concentrations of EEHDW were made by diluting the stock solution in the culture medium. The final concentration of DMSO in the medium was $<0.5 \%$.

Cell culture. Human colon carcinoma HT-29 cells were obtained from American Type Culture Collection (ATCC, Manassas, VA, USA). The cells were grown in DMEM containing $10 \%(\mathrm{v} / \mathrm{v}) \mathrm{FBS}$ and $100 \mathrm{U} / \mathrm{ml}$ penicillin and $100 \mu \mathrm{g} / \mathrm{ml}$ streptomycin in a $37^{\circ} \mathrm{C}$ humidified incubator with $5 \% \mathrm{CO}_{2}$. The cells were subcultured at $80-90 \%$ confluency. Cells used in this study were subjected to no more than 20 cell passages.

Evaluation of cell viability by MTT assay. Cell viability was assessed by the 3-(4, 5-dimethylthiazol-2-yl)-2, 5-diphenyltetrazolium bromide (MTT) colorimetric assay. HT-29 cells were seeded into 96 -well plates at a density of $1.0 \times 10^{4}$ cells/ well in $0.1 \mathrm{ml}$ medium. The cells were treated with various concentrations of EEHDW for $24 \mathrm{~h}$ or with $4 \mathrm{mg} / \mathrm{ml}$ of EEHDW for different periods of time. Treatment with $0.5 \%$ DMSO was included as vehicle control. At the end of the treatment, $10 \mu 1$ MTT $(5 \mathrm{mg} / \mathrm{ml}$ in phosphate buffered saline, PBS) were added to each well, and the samples were incubated for an additional $4 \mathrm{~h}$ at $37^{\circ} \mathrm{C}$. The purple-blue MTT formazan precipitate was dissolved in $100 \mu 1 \mathrm{DMSO}$. The absorbance was measured at $570 \mathrm{~nm}$ using an ELISA reader (BioTek, Model EXL800, USA).

Observation of morphologic changes. HT-29 cells were seeded into 6 -well plates at a density of $2.0 \times 10^{5}$ cells/well in $2 \mathrm{ml}$ medium. The cells were treated with various concentrations of EEHDW for $24 \mathrm{~h}$. Cell morphology was observed using a phase-contrast microscope (Olympus, Japan). The photographs were taken at a magnification of $\mathrm{x} 200$.

Detection of apoptosis by flow cytometry analysis with Annexin V/PI staining. After incubated with various concentrations of EEHDW, apoptosis of HT-29 cells was determined by flow cytometry analysis using a fluorescence-activated cell sorting (FACS) caliber (Becton-Dickinson, CA, USA) and Annexin V-fluorescein isothiocyanate (FITC)/propidium iodide (PI) kit (Becton-Dickinson). Staining was performed according to the manufacturer's instructions. The percentage of cells in early apoptosis was calculated by Annexin Vpositivity and PI-negativity, while the percentage of cells in late apoptosis was calculated by Annexin V-positivity and PI-positivity.

Detection of DNA fragmentation by gel electrophoresis. DNA fragmentation was determined using DNA ladder detection kit (Invitrogen), following the manufacturer's instructions. Briefly, HT-29 cells were detached from the plates by scraping 
and washed in PBS. Cells $\left(2 \times 10^{6}\right)$ were resuspended in $70 \mu \mathrm{l}$ TE lysis buffer and the enzyme A solution provided in the kit was added to the crude lysate and incubated at $37^{\circ} \mathrm{C}$ for $10 \mathrm{~min}$. The resultant sample was then treated with enzyme $\mathrm{B}$ solution and incubated at $50^{\circ} \mathrm{C}$ for $30 \mathrm{~min}$. DNA was precipitated with ammonium acetate solution and pre-cooled absolute ethanol followed by centrifugation at $16,000 \mathrm{x}$ g for $10 \mathrm{~min}$. The DNA pellet was washed with $70 \%$ ethanol and re-centrifuged at $16,000 \mathrm{x} \mathrm{g}$ for $10 \mathrm{~min}$. Precipitated DNA was resuspended in the provided DNA suspension buffer and analyzed after separation by gel electrophoresis $(1.5 \%$ agarose). The DNA bands were examined using a Gel Documentation System (BioRad, Model Gel Doc 2000, USA).

Measurement of mitochonrial membrane potential $(\Delta \psi m)$ by flow cytometry analysis with $\mathrm{JC}-1$ staining. $\mathrm{JC}-1$ is a cationic dye that exhibits potential mitochondria-dependent accumulation, indicated by a fluorescence emission shift from green to red, which thus can be used as an indicator of mitochondrial potential. In this experiment, $1 \times 10^{6}$ treated HT-29 cells were resuspended after trypsinization in $1 \mathrm{ml}$ of medium and incubated with $10 \mu \mathrm{g} / \mathrm{ml}$ of JC-1 (Invitrogen) at $37^{\circ} \mathrm{C}, 5 \%$ $\mathrm{CO}_{2}$, for $30 \mathrm{~min}$. Both red and green fluorescence emissions were analyzed by flow cytometry after JC- 1 staining.

Analysis of caspase activation. The activities of caspase-3 and -9 were determined by a colorimetric assay using the caspase- 3 and -9 activation kits (Invitrogen), following the manufacturer's instructions. Briefly, after treated with various concentrations of EEHDW for $24 \mathrm{~h}, \mathrm{HT}-29$ cells were lysed with provided lysis buffer for $30 \mathrm{~min}$ on ice. The lysed cells were centrifuged at $16,000 \mathrm{x}$ g for $10 \mathrm{~min}$, and $100 \mu \mathrm{g}$ of the protein were incubated with $50 \mu 1$ of the colorimetric tetrapeptides, Asp-Glu-Val-Asp (DEAD)-p-nitroaniline (pNA) (specific substrate of caspase-3) or Leu-Glu-His-Asp (LEHD)pNA (specific substrate of caspase-9) at $37^{\circ} \mathrm{C}$ in the dark for $2 \mathrm{~h}$. Samples were read at $405 \mathrm{~nm}$ in an ELISA reader (BioTek, Model EXL800, USA). The data were normalized to the activity of the caspases in control cells (treated with $0.5 \%$ DMSO vehicle) and presented as fold of control.

RNA extraction and RT-PCR analysis. HT-29 cells $\left(2 \times 10^{5}\right)$ were seeded into 6-well plates in $2 \mathrm{ml}$ medium and treated with various concentrations of EEHDW for $24 \mathrm{~h}$. Total RNA from HT-29 cells was isolated with TRIzol reagent (Invitrogen). Oligo(dT)-primed RNA (1 $\mu \mathrm{g})$ was reversetranscribed with SuperScript II reverse transcriptase (Promega) according to the manufacturer's instructions. The obtained cDNA was used to determine the mRNA amount of Bcl-2 or Bax by PCR with Taq DNA polymerase (Fermentas). GAPDH was used as an internal control. The primers used for amplification of Bcl-2, Bax and GAPDH transcripts are as follows: Bcl-2 forward 5'-CAG CTG CAC CTG ACG CCC TT-3 and reverse 5'-GCC TCC GTT ATC CTG GAT CC-3'; Bax forward 5'-TGC TTC AGG GTT TCA TCC AGG-3' and reverse 5'-TGG CAA AGT AGA AAA GGG CGA-3'; GAPDH forward 5'-GT CAT CCA TGA CAA CTT TGG-3' and reverse 5'-GA GCT TGA CAA AGT GGT CGT-3'.

Western blot analysis. HT-29 cells $\left(2 \times 10^{5}\right)$ were seeded into 6 -well plates in $2 \mathrm{ml}$ medium and treated with various con-
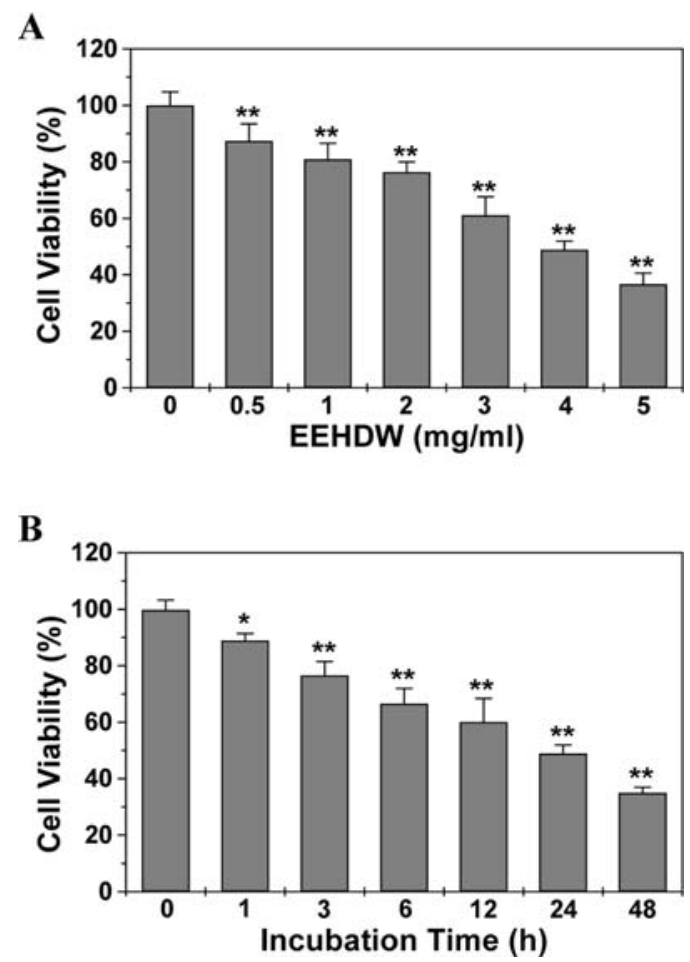

Figure 1. Effect of EEHDW on cell viability of HT-29 cells. (A) HT-29 cells were treated with the indicated concentrations of EEHDW for $24 \mathrm{~h}$. (B) Cells were treated with $4 \mathrm{mg} / \mathrm{ml}$ of EEHDW for the indicated time periods. Cell viability was determined by the MTT assay. The data were normalized to the viability of control cells ( $100 \%$, treated with $0.5 \%$ DMSO vehicle) Data are averages with S.D. (error bars) from at least three independent experiments. ${ }^{*} \mathrm{P}<0.05,{ }^{* *} \mathrm{P}<0.01$, significant versus control cells.

centrations of EEHDW for $24 \mathrm{~h}$. The treated cells were lysed with mammalian cell lysis buffer (M-PER; Thermo Scientific, Rockford, IL, USA) containing protease and phosphatase inhibitor cocktails (EMD Biosciences and Sigma Chemical, USA, respectively), and the lysates were separated by Nusep 12\% LongLife Tris Glycine iGels (Nusep Ltd., Australia) under a reducing condition using $200 \mathrm{~V}$ for $1 \mathrm{~h}$. The proteins were then electrophoretically transferred onto nitrocellulose membranes using the iBlot Western detection stack/iBlot dry blotting system (Invitrogen). Membranes were blocked for 30 min with agitation at RT in SuperBlock T20 (TBS) blocking buffer (Thermo Scientific, Rockford, IL). Membranes were washed in TBS with $0.25 \%$ Tween-20 (TBST) and exposed to primary antibodies against Bcl-2 or Bax (1:1000, Cell Signaling Technology) overnight at $4^{\circ} \mathrm{C}$ with rocking. ß-actin (1:1000, Cell Signaling Technology) was also measured as an internal control for protein loading. After membranes were washed in TBST, secondary horseradish peroxidase (HRP)-conjugated antibodies (anti-rabbit, Cell Signaling Technology) were added at 1:2500 dilution for $1 \mathrm{~h}$ at room temperature and the membranes were washed again in TBST. Blots were developed using Super Signal Pico Substrate (Thermo Scientific, Rockford, IL, USA), and images were taken using a Kodak image station 400R (Kodak, Rochester, NY, USA).

Statistical analysis. All data are the means of three determinations and data were analyzed using the SPSS package for 

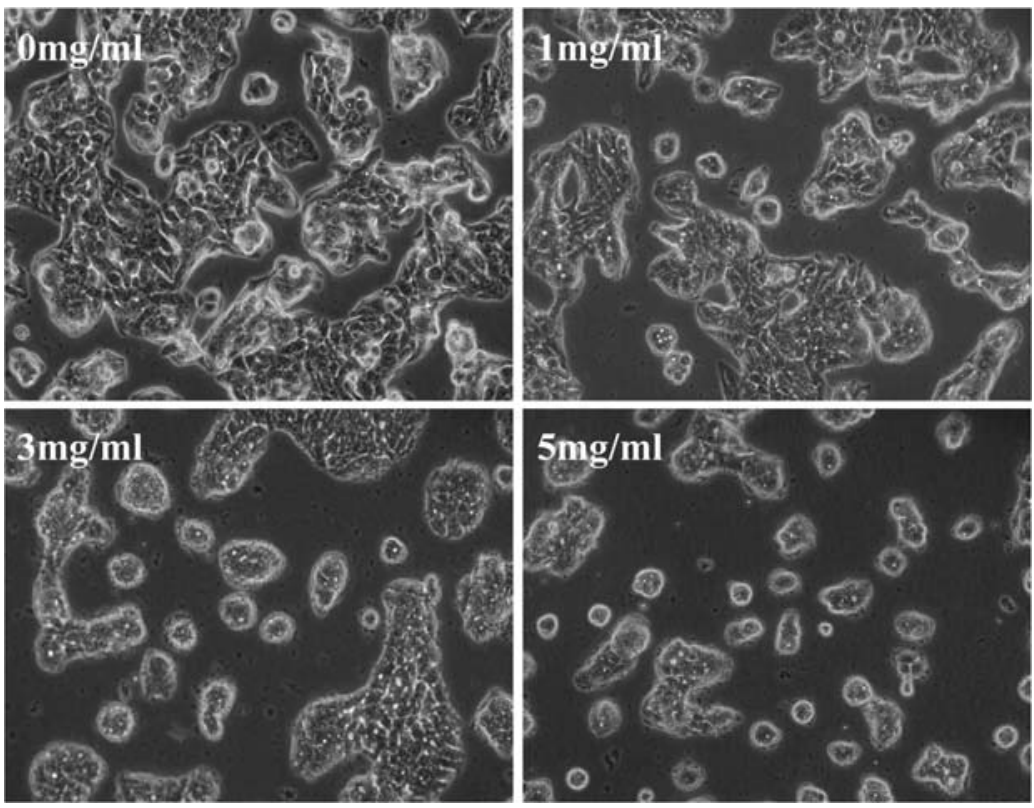

Figure 2. Effect of ethanol extract of Hedyotis Diffusa Willd (EEHDW) on the morphological changes of HT-29 cells. HT-29 cells were treated with the indicated concentrations of EEHDW for $24 \mathrm{~h}$ and morphological changes were observed using phase-contrast microscopy. The photographs were taken at a magnification of x200. Images are representative of three independent experiments.

Windows (Version 11.5). Statistical analysis of the data was performed with Student's t-test and ANOVA. Differences with $\mathrm{P}<0.05$ were considered statistically significant.

\section{Results}

EEHDW inhibits the growth of HT-29 cells. The effect of EEHDW on the viability of HT-29 cells was determined by MTT assay. As shown in Fig. 1A, treatment with $0.5-5 \mathrm{mg} / \mathrm{ml}$ of EEHDW for $24 \mathrm{~h}$ dose-dependently reduced cell viability by $13-63 \%$ compared to untreated control cells $(\mathrm{P}<0.01)$, with an estimated half-maximal inhibitory concentration $\left(\mathrm{IC}_{50}\right)$ value of $4 \mathrm{mg} / \mathrm{ml}$. The cell viability was decreased to $37 \%$ at the highest concentration of EEHDW $(5 \mathrm{mg} / \mathrm{ml})$ in this study. We also evaluated the effect of $4 \mathrm{mg} / \mathrm{ml}$ of EEHDW ( $\mathrm{IC}_{50}$ value) on cell viability with incubation for different periods of time. As shown in Fig. 1B, treatment with $4 \mathrm{mg} / \mathrm{ml}$ of EEHDW led to a gradual decrease in cell viability with the increase of exposure time. These results suggest that EEHDW inhibits HT-29 cell growth or viability in a dose- and time-dependent manner. To further verify these results, we evaluated the effect of EEHDW on HT-29 cell morphology via phase-contrast microscopy, since cell morphology in culture is indicative of the healthy status of the cells. As shown in Fig. 2, untreated HT-29 cells appeared as densely packed and disorganized multilayers, whereas after incubation with various concentrations of EEHDW for $24 \mathrm{~h}$ many of the cells became rounded and shrunken, and detached from each other or floated in the medium. In addition, with $24 \mathrm{~h}$ exposure to EEHDW, the cells became less confluent. Taken together, these data demonstrate that EEHDW inhibits the growth of HT-29 cells.

EEHDW induces apoptosis of HT-29 cells. To determine whether the cell-growth suppressive effect of EEHDW is due to apoptosis, we examined EEHDW's pro-apoptotic activity in HT-29 cells via Annexin-V/PI staining followed by FACS analysis (Fig. 3A). In this assay, Annexin V/PI doublenegative population (labeled as LL in the FACS diagram) indicates viable cells; Annexin V-positive/PI-negative or Annexin V/PI double-positive population (labeled as LR or UR in the FACS diagram) represents cells undergoing early or late apoptosis, respectively. As shown in Fig. 3A and B, the percent of cells undergoing apoptosis following treatment with $0,1,3$ and $5 \mathrm{mg} / \mathrm{ml}$ of EEHDW (including the early and late apoptotic cells) was $12,22,28$ and $40 \%$, respectively $(\mathrm{P}<0.05$, versus untreated control cells $)$. This indicates that EEHDW treatment induces HT-29 cell apoptosis in a dosedependent manner. To confirm the pro-apoptotic function of EEHDW, we investigated the effect of EEHDW on cellular DNA fragmentation, a typical feature of apoptosis. As shown in Fig. 3C, DNA extracted from HT-29 cells treated with $4 \mathrm{mg} / \mathrm{ml}$ of EEHDW ( $\mathrm{IC}_{50}$ value) for $24 \mathrm{~h}$ displayed a characteristic ladder pattern of discontinuous DNA fragments.

EEHDW induces the loss of mitochondrial potential $(\Delta \psi m)$ and the activation of caspases- 9 and -3 . The mitochondriondependent pathway is the most common apoptotic pathway in vertebrate animal cells. The mitochondrial membrane permeabilization, accompanied by the collapse of electrochemical gradient across the mitochondrial membrane, is one of the key events during cellular apoptosis $(32,33)$. This results in the release of numerous apoptogenic proteins, such as cytochrome $\mathrm{c}$, from the mitochondria triggering the activation of caspases- 9 and -3 , and eventually inducing apoptosis. To investigate the mechanism of how EEHDW induces HT-29 cell apoptosis, we used FACS analysis with JC-1 staining to examine the change in mitochondrial membrane potential after EEHDW treatment. JC-1 is a lipophilic, cationic dye that selectively enters into mitochondria. In 
A

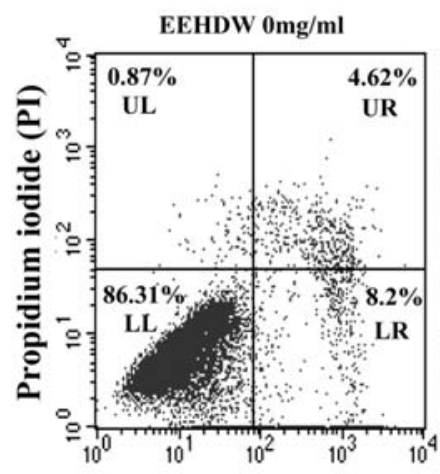

EEHDW 1mg/ml

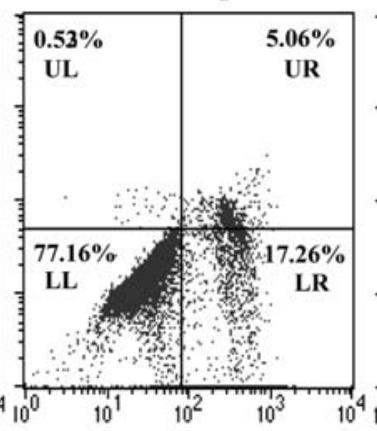

EEHDW $3 \mathrm{mg} / \mathrm{ml}$

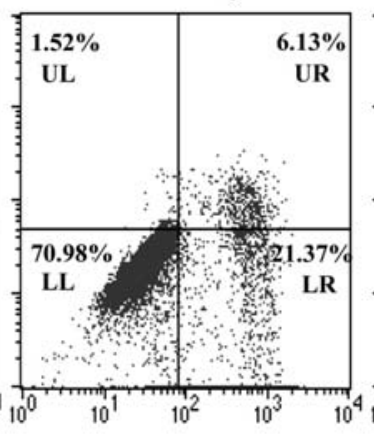

EEHDW 5mg/ml

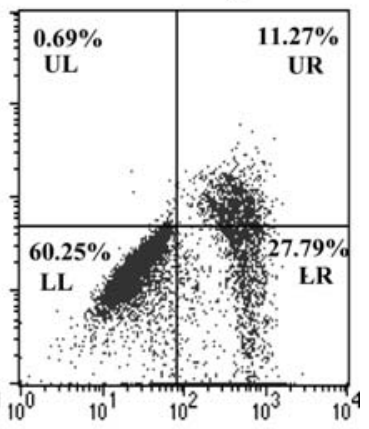

Annexin V

B

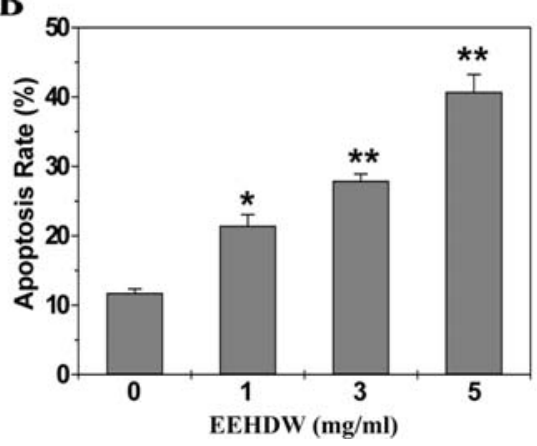

C

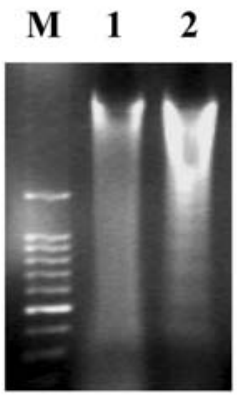

Figure 3. Effect of EEHDW on the apoptosis of HT-29 cells. (A) After treatment with the indicated concentrations of EEHDW for 24 h, HT-29 cells were collected and stained with Annexin V/PI followed by FACS analysis. Representative FACS analysis scatter-grams of Annexin V/PI staining displays four different cell populations labeled as: double-negative stained cells (LL, lower left) indicating live cell population; Annexin V-positive/PI-negative stained cells (LR, lower right) and Annexin V/PI double-positive stained cells (UR, upper right) representing early apoptosis and late apoptosis, respectively; Annexin V-negative and PI-positive stained cells (UL, upper left) showing dead cells. The data shown are representative of three independent experiments. (B) Quantification of FACS analysis. The data shown are averages with S.D. (error bars) from three independent experiments. ${ }^{*} \mathrm{P}<0.05$, ${ }^{* *} \mathrm{P}<0.01$, significant versus control cells (treated with 0.5\% DMSO vehicle). (C) EEHDW-induced DNA fragmentation. HT-29 cells were treated with 4 mg/ml of EEHDW for $24 \mathrm{~h}$. DNA was extracted and analyzed by $1.5 \%$ agarose gel electrophoresis. M: 100 bp DNA marker, lane 1: control, lane 2: 4 mg/ml EEHDW.

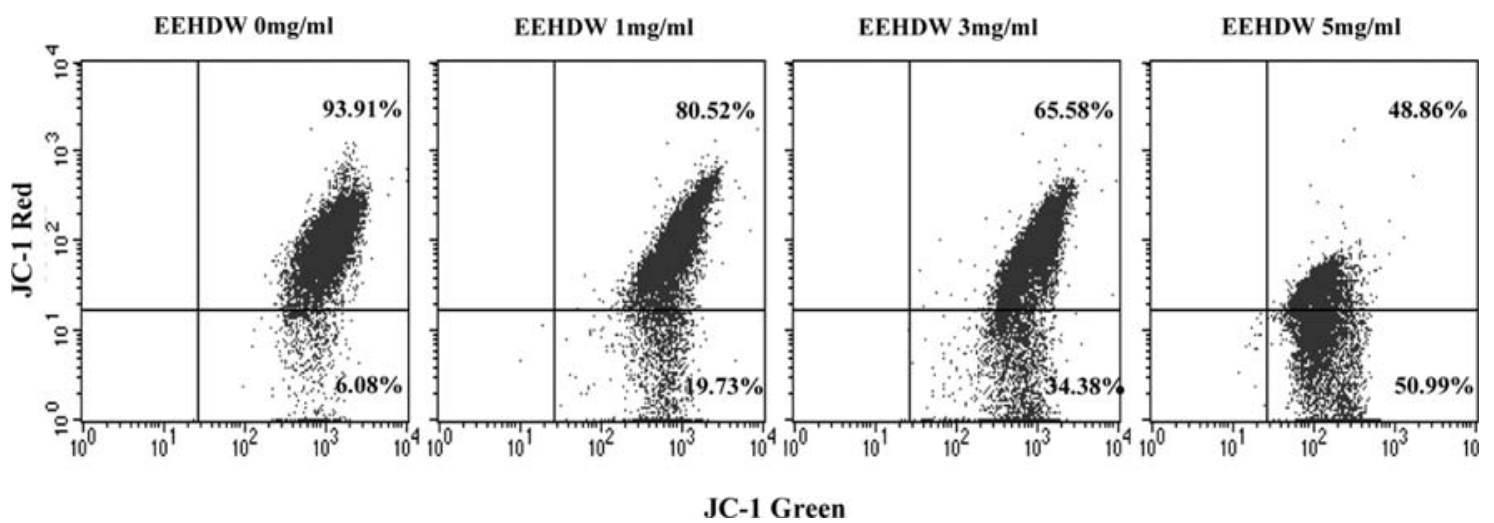

Figure 4. Effect of EEHDW on the loss of mitochondrial membrane potential in HT-29 cells. HT-29 cells were treated with the indicated concentrations of EEHDW for $24 \mathrm{~h}$ and stained with JC-1. The mean JC-1 fluorescence intensity was detected using FACS analysis. Data are representative of three independent experiments.

healthy cells with high mitochondrial potential, JC-1 forms J-aggregates with intense red fluorescence $(590 \mathrm{~nm})$, whereas under apoptotic condition, the mitochondrial membrane potential collapses, so that JC-1 does not accumulate within the mitochondria but remains in the cytoplasm in monomeric form showing green fluorescence $(525 \mathrm{~nm})$. These fluores- cence differences can by detected by FACS analysis using JC-1 green and red channels. As shown in Fig. 4, JC-1 fluorescence was shifted from a JC-1-green-bright/JC-1-redbright signal in untreated HT-29 cells to a JC-1-greenbright/JC-1-red-dim signal in cells treated with EEHDW in a dose-dependent fashion, indicating EEHDW-induced loss of 
A

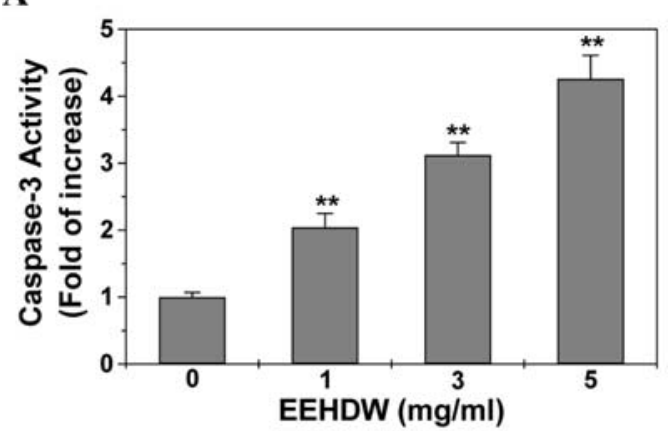

B

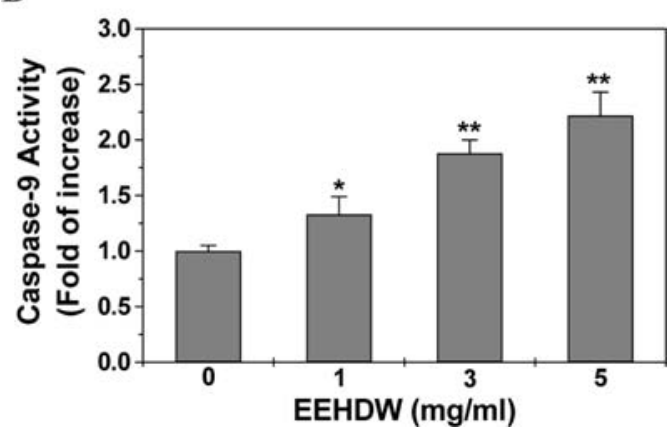

Figure 5. Effect of EEHDW on the activity of caspases in HT-29 cells. The cells were treated with the indicated concentrations of EEHDW for $24 \mathrm{~h}$. Caspase- 3 and -9 activities were determined by a colorimetric assay. The data were normalized to the caspase activities within control cells (treated with $0.5 \%$ DMSO vehicle) and represented as fold of control. Data are averages with S.D. (error bars) from at least three independent experiments. ${ }^{*} \mathrm{P}<0.05,{ }^{* *} \mathrm{P}<0.01$, significant versus control cells.

mitochondrial membrane potential in HT-29 cells. To identify the downstream effectors in the apoptotic signaling pathway, the activation of caspases- 9 and -3 was examined by a colorimetric assay using specific chromophores, DEVDpNA (specific substrate of caspase-3) and LEHD-pNA (specific substrate of caspase-9). As showed in Fig. 5A and B, EEHDW treatment significantly and dose-dependently induced activation of both caspases- 9 and -3 in HT-29 cells $(\mathrm{P}<0.01$ or 0.05 , versus untreated control cells). These data suggest that EEHDW promotes HT-29 cell apoptosis via the mitochondrion-dependent pathway.

EEHDW regulated the expression of anti-apoptotic Bcl-2 and pro-apoptotic Bax. Bcl-2 family proteins are key regulators of mitochondrion-mediated apoptosis, including anti-apoptotic members such as Bcl-2 and pro-apoptotic members such as Bax. Tissue homeostasis is maintained by controlling the ratio of active anti- and pro-apoptotic Bcl-2 family proteins. Higher $\mathrm{Bcl}-2$-to-Bax ratio by aberrant expression of the proteins is found commonly in various cancers. To further study the mechanism of EEHDW's anti-cancer activity, we performed RT-PCR and Western blotting to examine the mRNA and protein expression of $\mathrm{Bcl}-2$ and Bax in EEHDW-treated HT-29 cells. The results of the RT-PCR assay showed that EEHDW treatment profoundly increased Bax and reduced Bcl-2 mRNA expression in HT-29 cells (Fig. 6A); and the pattern of protein expression of $\mathrm{Bax}$ and $\mathrm{Bcl}-2$ was similar to their respective mRNA levels (Fig. 6B). This suggests that
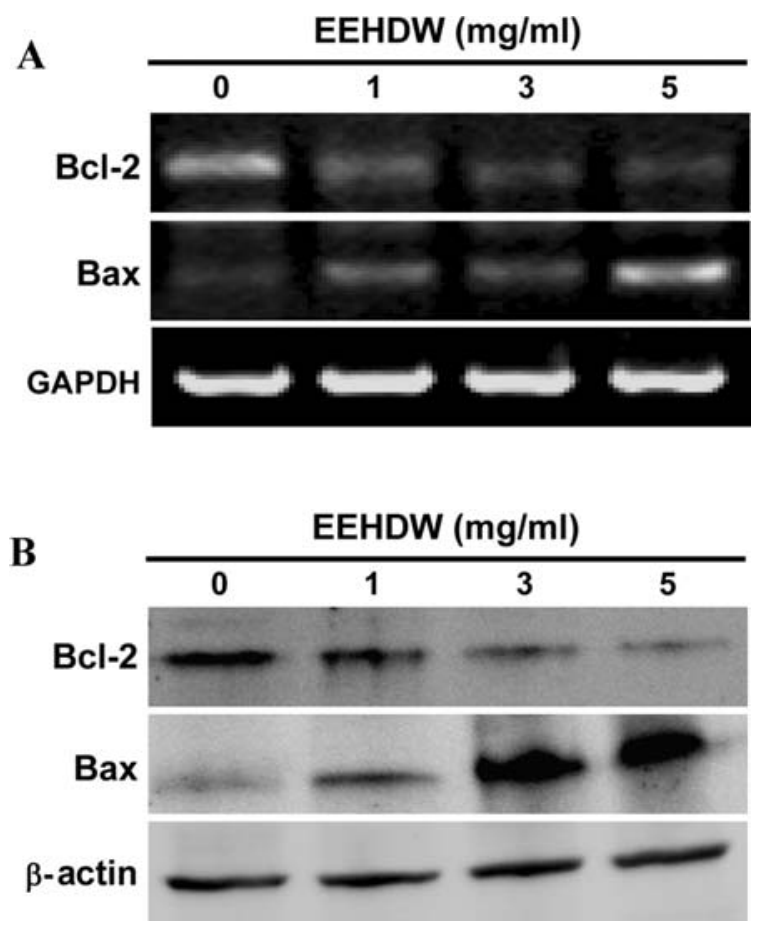

Figure 6. Effect of EEHDW on the expression of Bax and Bcl-2 in HT-29 cells. Cells were treated with the indicated concentrations of EEHDW for $24 \mathrm{~h}$. (A) The mRNA levels of Bax and Bcl-2 in EEHDW-treated and untreated cells were determined by RT-PCR. (B) The protein expression levels of Bax and $\mathrm{Bcl}-2$ were analyzed by Western blotting. GAPDH and $\beta$-actin were used as the internal controls for the RT-PCR or Western blotting assays, respectively. Data are representative of three independent experiments.

EEHDW induces mitochondrion-dependent apoptosis in HT-29 cells through the regulation of expression of Bcl-2 family proteins.

\section{Discussion}

Cancer cells are characterized by an unregulated increase in cell proliferation and/or a reduction in cell apoptosis (15). In addition, disrupted apoptosis contributes to drug resistance of tumor cells, which has become a significant obstacle for the successful management of patients with malignant tumors including colorectal cancer (CRC) (2-4). Moreover, many currently used anti-cancer agents contain intrinsic and potent cytotoxicity to normal cells, which limits their long-term use and thereby their therapeutic effectiveness (5). These problems highlight the urgent need for the development of novel cancer chemotherapies. Since natural products, such as traditional Chinese herbal medicines (TCM), have relatively fewer sideeffects as compared to modern chemotherapeutics and have long been used clinically to treat various types of diseases including cancer (8-11), discovering naturally occurring agents with pro-apoptotic activities is a promising approach for anticancer treatment.

Hedyotis Diffusa Willd is an important traditional heatclearing and detoxifying Chinese herb used in TCM formulations, with many reported pharmacological applications. Recently, Hedyotis Diffusa Willd has been demonstrated to be clinically effective in treating various cancers including CRC (12-14). However, the mode of action for its anti-tumor 
is still largely unknown. Therefore, before Hedyotis Diffusa Willd can be further developed as an anti-cancer agent, its anti-tumor activity and underlying molecular mechanism should first be elucidated.

Here we reported for the first time that the ethanol extract of Hedyotis Diffusa Willd (EEHDW) reduces the viability and inhibits growth of human colon carcinoma HT-29 cells in a dose- and time-dependent fashion. Furthermore, we demonstrated that these effects on HT-29 cells result from the induction of apoptosis by EEHDW.

Apoptosis manifests in two major pathways. For the intrinsic pathway, death signals are integrated at the level of the mitochondria (therefore, also this pathway is referred to as mitochondrion-dependent). For the extrinsic pathway, death signals are mediated through cell surface receptors. Both pathways eventually lead to the activation of caspases and nucleases, resulting in the destruction of the cell (15-17). Mitochondrial outer membrane permeabilization (MOMP) is a key commitment step in the induction of cellular apoptosis, since it is the point of convergence for a large variety of intracellular apoptotic signaling pathways leading to the release of many apoptogenic proteins from the mitochondrial intermembrane space. During the process of MOMP, the electrochemical gradient across the mitochondrial membrane collapses. Therefore, the loss of mitochondrial membrane potential is a hallmark for apoptosis. Our data clearly showed that treatment with EEHDW leads to a collapse of mitochondrial membrane potential.

Caspases, represented by a family of cysteine proteases, are the key proteins that modulate the apoptotic response. Caspase- 3 is a key executioner of apoptosis, which is activated by an initiator caspase such as caspase- 9 during mitochondrionmediated apoptosis. In this study, we found that EEHDW induces the activation of both caspase- 9 and -3 in HT-29 cells in a dose-dependent manner. Thus, EEHDW-induced HT-29 cell death is accompanied by an increase in the activities of caspases- 9 and -3 , which then stimulates the molecular cascade for apoptosis.

Mitochondrion-dependent apoptosis is mainly regulated by $\mathrm{Bcl}-2$ family proteins. MOMP is thought to occur through the formation of pores in the mitochondria by pro-apoptotic Bax-like proteins, which can be inhibited by anti-apoptotic Bcl-2-like members. Therefore, the ratio of Bax to Bcl-2 is a critical for determining the fate of cells. In this study, we demonstrated that EEHDW treatment dose-dependently enhances Bax mRNA expression and reduces Bcl-2 mRNA expression in HT-29 cells. This indicates that EEHDW induces apoptosis by affecting the ratio of $\mathrm{Bax} / \mathrm{Bcl}-2$ at transcriptional level. We further studied the role of EEHDW on the expression of proteins involved in the mitochondrial pathway. The results showed that EEHDW treatment up-regulates Bax protein expression and down-regulates $\mathrm{Bcl}-2$ protein expression, which is in accordance with the pattern of their mRNA expression after EEHDW treatment.

In conclusion, our data for the first time demonstrate that EEHDW inhibits the growth of and induces HT-29 cell apoptosis via the mitochondrion-dependent pathway. These results suggest that Hedyotis Diffusa Willd may be a potential novel therapeutic agent for the treatment of colorectal and other cancers.

\section{Acknowledgments}

This work was supported by Open Fund of Fujian Key Laboratory of Integrative Medicine on Geriatrics (2008J1004) and Developmental Fund of Chen Keji Integrative Medicine (CKJ 2008056).

\section{References}

1. Longley DB, Allen WL and Johnston PG: Drug resistance, predictive markers and pharmacogenomics in colorectal cancer. Biochim Biophys Acta 1766: 184-196, 2006.

2. Johnston, PG and Kaye S: Capecitabine: a novel agent for the treatment of solid tumors. Anticancer Drugs 12: 639-646, 2001.

3. Giacchetti S, Perpoint B, Zidani R, Le Bail N, Faggiuolo R, Focan C, Chollet P, Llory JF, Letourneau Y, Coudert B, Bertheaut-Cvitkovic F, Larregain-Fournier D, Le Rol A, Walter S, Adam R, Misset JL and Lévi F: Phase III multicenter randomized trial of oxaliplatin added to chronomodulated fluorouracilleucovorin as first-line treatment of metastatic colorectal cancer. J Clin Oncol 18: 136-147, 2000.

4. Douillard JY, Cunningham D, Roth AD, Navarro M, James RD, Karasek P, Jandik P, Iveson T, Carmichael J, Alakl M, Gruia G, Awad L and Rougier P: Irinotecan combined with fluorouracil compared with fluorouracil alone as first-line treatment for metastatic colorectal cancer: a multicentre randomised trial. Lancet 355: 1041-1047, 2000

5. Boose G and Stopper H: Genotoxicity of several clinically used topoisomerase II inhibitors. Toxicol Lett 116: 7-16, 2000.

6. Park HR, Tomida A, Sato S, Tsukumo Y, Yun J, Yamori T, Hayakawa Y, Tsuruo T and Shin-ya K: Effect on tumor cells of blocking survival response to glucose deprivation. J Natl Cancer Inst 96: 1300-1310, 2004.

7. Ryoo IJ, Park HR, Choo SJ, Hwang JH, Park YM, Bae KH, Shinya K and Yoo ID: Selective cytotoxic activity of valinomycin against HT-29 human colon carcinoma cells via down-regulation of GRP78. Biol Pharm Bull 29: 817-820, 2006.

8. Newman DJ, Cragg GM and Snader KM: The influence of natural products upon drug discovery. Nat Prod Rep17: 215-234, 2000.

9. Louis Jeune MA, Kumi-Diaka J and Brown J: Anticancer activities of pomegranate extracts and genistein in human breast cancer cells. J Med Food 8: 469-475, 2005.

10. Sausville EA: Versipelostatin-unfolding an unsweetened death. J Natl Cancer Inst 96: 1266-1267, 2004.

11. Won HJ, Han CH, Kim YH, Kwon HJ, Kim BW, Choi JS and Kim KH: Induction of apoptosis in human acute leukemia Jurkat $\mathrm{T}$ cells by Albizzia julibrissin extract is mediated via mitochondria-dependent caspase-3 activation. J Ethnopharmacol 106: 383-389, 2006

12. Song LR: Zhonghuabencao. Vol 61. Shanghai Science and Technology Press, Shanghai, pp433, 1999.

13. Yang JJ, Hsu HY, Ho YH and Lin CC: Comparative study on the immunocompetent activity of three different kinds of PehHue-Juwa-Chi-Cao, Hedyotis diffusa, H. corymbosa and Mollugo pentaphylla after sublethal whole body $\mathrm{x}$-irradiation. Phytother Res 11: 428-432, 1997.

14. Li R, Zhao HR and Lin YM: Anti-tumor effect and protective effect on chemotherapeutic damage of water soluble extracts from Hedyotis diffusa. J Chin Pharmaceu Sci 11: 54-58, 2002.

15. Adams JM and Cory S: The Bcl-2 apoptotic switch in cancer development and therapy. Oncogene 26: 1324-1337, 2007.

16. Cory S and Adams JM: The Bcl-2 family: regulators of the cellular life-of-death switch. Nat Rev Cancer 2: 647-656, 2002.

17. Reed JC: Mechanisms of apoptosis. Am J Pathol 157: 1415-1430, 2000.

18. Vaux DL and Korsmeyer SJ: Cell death in development. Cell 96: 245-254, 1999.

19. Gross A, McDonnell JM and Korsmeyer SJ: Bcl-2 family members and the mitochondria in apoptosis. Genes Dev 13: 1899-1911, 1999.

20. Hsu YT, Wolter K and Youle RJ: Cytosol to membrane redistribution of members of the Bcl-2 family during apoptosis. Proc Natl Acad Sci USA 94: 3668-3672, 1997.

21. Wolter KG, Hsu YT, Smith CL, Nechushtan A, Xi XG and Youle RJ: Movement of Bax from the cytosol to mitochondria. J Cell Biol 139: 1281-1292, 1997. 
22. Wei MC, Lindsten T, Mootha VK, Weiler S, Gross A, Ashiya M, Thompson CB and Kormeryer SJ: tBid, a membrane-targeted death ligand, oligomerizes Bak to release cytochrome c. Genes Dev 14: 2060-2071, 2000.

23. Antonsson B, Montessuit S, Lauper S, Eskes R and Martinou JC: Bax oligomerization is required for channel-forming activity in liposomes and to trigger cytochrome $\mathrm{c}$ release from mitochondria. Biochem J 345: 271-278, 2000.

24. Jurgensmeier JM, Xie Z, Deveraux Q, Ellerby L, Bredesen D and Reed JC: Bax directly induces release of cytochrome $\mathrm{c}$ from isolated mitochondria. Proc Natl Acad Sci USA 95: 4997-5002, 1998.

25. Kluck RM, Bossy-Wetzel E, Green DR and Newmeyer DD: The release of cytochrome $\mathrm{c}$ from mitochondria: a primary site for Bcl-2 regulation of apoptosis. Science 275: 1132-1136, 1997.

26. Yang J, Liu X, Bhalla K, Kim CN, Ibrado AM, Cai J, Peng TI and Jones DP: Prevention of apoptosis by Bcl-2: release of cytochrome c from mitochondria blocked. Science 275: 1129-1132, 1997.

27. Thomenius MJ, Wang NS, Reineks EZ, Wang Z and Distelhorst $\mathrm{CW}$ : $\mathrm{Bcl}-2$ on the endoplasmic reticulum regulates Bax activity by binding to $\mathrm{BH} 3$-only proteins. J Biol Chem 278 : 6243-6250, 2003.
28. Antonsson B, Conti F, Ciavatta A, Montessuit S, Lewis S, Martinou I, Bernasconi L, Bernard A, Mermod JJ, Mazzei G, Maundrell K, Gambale F, Sadoul R and Martinou JC: Inhibition of Bax channel-forming activity by Bcl-2. Science 277: 370-372, 1997.

29. Youle RJ and Strasser A: The BCL-2 protein family: opposing activities that mediate cell death. Nat Rev Mol Cell Biol 9: 47-59, 2008.

30. Yip KW and Reed JC: Bcl-2 family proteins and cancer. Oncogene 27: 6398-6406, 2008.

31. Kitada S, Pedersen IM, Schimmer AD and Reed JC: Dysregulation of apoptosis genes in hematopoietic malignancies. Oncogene 21: 3459-3474, 2002.

32. Mantymaa P, Siitonen T, Guttorm T, Saily M, Kinnula V, Savolainen ER and Koistinen P: Induction of mitochondrial manganese superoxide dismutase confers resistance to apoptosis in acute myeloblastic leukaemia cells exposed to etoposide. Br J Haematol 108: 574-581, 2000.

33. Korper S, Nolte F, Rojewski MT, Thiel E and Schrezenmeier H: The $\mathrm{K}^{+}$channel openers diazoxide and NS1619 induce depolarization of mitochondria and have differential effects on cell $\mathrm{Ca}^{2+}$ in CD34+ cell line KG-1. Exp Hematol 31: 815-823, 2003. 